NOTE

\title{
The Heat of Mixing of Both Poly(vinyl nitrate) with Poly(vinyl acetate) and Poly(vinyl nitrate) with Poly(ethylene-co-vinyl acetate) Mixtures
}

\author{
Saburo AkIYAMA* and Katsuhiro MiasA** \\ Department of Industrial Chemistry, Faculty of Technology, \\ Tokyo University of Agriculture and Technology, \\ 2 Naka-cho, Koganei-shi, Tokyo 184, Japan.
}

(Received November 29, 1977)

\begin{abstract}
KEY WORDS Calorimetry / Compatible Polar Polymers / Exothermic Heat of Mixing / Heat of Solution / Compatibility /
\end{abstract}

A compatible binary system is generally understood to form a thermodynamically stable, single phase. Formation of this single phase under a constant temperature and pressure occurs with a decrease in free energy from individual two component system to single system. The free energy of mixing is expressed as follows;

$$
\Delta G_{\mathrm{M}}=\Delta H_{\mathrm{M}}-T \Delta S_{\mathrm{MI}}
$$

where $\Delta G_{\mathrm{M}}=$ the change of free energy on mixing, $\Delta H_{\mathrm{M}}=$ the change of enthalpy on mixing, $\Delta S_{\mathrm{M}}=$ the change of entropy on mixing, and $T=$ absolute temperature.

As to polymer mixing, $\Delta S_{\mathrm{M}}$ is considered to be very small $(T \Delta S=0.0083 \mathrm{cal} / 2 \mathrm{~g})$, the compatibility being surely attainable when the enthalpy of mixing has negative value.

Binary polar polymer systems of poly(vinyl nitrate) (PVN)-poly (vinyl acetate) (PVAc) and PVN-poly(ethylene-co-vinyl acetate) (86wt \% vinyl acetate) (EVAc) have been examined with various methods. ${ }^{2-5}$ The results show that these two systems are compatible pairs by the dynamic $\operatorname{loss}^{2}$ and the dielectric loss ${ }^{3}$ measurements.

In this study, the precise thermal measurement was performed to confirm the compatibility of these systems thermodynamically.

* Present Address: Laboratory of Chemistry, Faculty of General Education, Tokyo University of Agriculture and Technology, 3-5-8, Saiwai-cho, Fuchüshi, Tokyo 183, Japan.

** Present Address: Tokyo Kenkyusho, Showa Kobunshi Co., Ltd., Ikegami, Ohta-ku, Tokyo 146, Japan.
Poly(vinyl nitrate) (PVN) was synthesized from poly(vinyl alcohol) (PVA) according to the method described in our previous publication. ${ }^{5}$ The degree of esterification was $94.8 \mathrm{~mol} \%$ with a $[\eta]=0.90 \mathrm{~d} l / \mathrm{g}$ from acetone solution. The viscosity average degree of polymerization $\left(P_{v}\right)$ of the PVA used was 1700 . Poly(vinyl acetate) (PVAc) was obtained as a commercial product with a $P_{v}$ of 1800. Ethylene-vinyl acetate copolymer (EVAc) was furnished by Nippon Gosei Kagaku Co., Ltd., with a $P_{v}$ of 1350 . The $P_{v}$ of these two polymers were determined by viscosity method. ${ }^{6}$ All of these unfractionated polymers were purified by reprecipitation from acetone solutions with distilled water several times. Polymer mixtures were prepared from mixed solutions of polymer pairs by evaporating the solvent acetone. The casting films were dried at $40^{\circ} \mathrm{C}$ in vacuo for more than two weeks untill constant weights were attained. Amorphous broad patterns of X-ray diffraction are observed in both PVN and EVAc films, and also in both blend films.

A Calvet $^{7}$ conduction-type twin calorimeter constructed by Miyata and his coworkers ${ }^{8}$ at this university was used to measure the heat of solution. A tiny piece of the sample film weighing $0.09 \mathrm{~g}$ was placed in the sample holder and covered with a cap sealed by mercury. The same operation was done at the reference cell without placing the sample. Forty grams of distilled acetone were poured into the twin cells. After temperature equilibrium of both cells was reached, the sample was dissolved and the temperature dif- 


\section{S. Akiyama and K. Miasa}

Table I. Heat of blending of the mixtures at $30^{\circ} \mathrm{C}$

\begin{tabular}{lcccc}
\hline \multicolumn{1}{c}{ Samples } & $\begin{array}{c}\text { Weight } \\
\text { ratio }\end{array}$ & $\begin{array}{c}\text { Joul's heat, } \\
\text { cal }\end{array}$ & $\begin{array}{c}\text { Heat of solution, } \\
\text { cal/g }\end{array}$ & $\begin{array}{c}\Delta Q_{\mathrm{M}}\left(=-\Delta H_{\mathrm{M}}\right) \\
\text { Heat of blending, } \\
\text { cal/g }\end{array}$ \\
\hline Blended PVN/PVAc & $5 / 5$ & 0.141 & 2.21 & $0.70 \pm 0.1$ \\
Unblended PVN+PVAc & $5 / 5$ & 0.141 & 2.91 & $0.38 \pm 0.1$ \\
\hline Blended PVN/EVAc & $5 / 5$ & 0.188 & 2.18 & 0.1 \\
Unblended PVN+EVAc & $5 / 5$ & 0.141 & 2.56 & 0.36 \\
\hline
\end{tabular}

ference between the twin cells was measured with a thermomodule and recorded continuously for $4 \mathrm{~h}$ until the sample was dissolved completely, and equilibrium established.

In principle, the heat of solution is obtained by comparison of the integrated area of the thermogram and that of the thermogram from supplied electric energy. Thus, the heat of solution, $Q$, can be calculated from the following equation:

$$
Q=1 / m\left(S / S_{0}\right) Q_{0}
$$

where $S$ and $S_{0}$ are the areas enclosed by the curves and base lines in the thermograms, which correspond to the heat of solution, $Q$, and Joule's heat, $Q_{0}$, respectively and $m$ is the weight of the sample dissolved. The Joule's heat is represented by the following equation:

$$
Q_{0}=R I^{2} t
$$

where $R$ is the resistance of wire, $I$ the electric current and $t$ the time of the passage of the current. Here, $R=128.5 \Omega$ and $I=5.05 \times 10^{-3} \mathrm{~A}$. The water tank $\left(60^{2} \times \pi \times 90 \mathrm{~cm}^{3}\right)$ was thermostated at $30 \pm 0.015^{\circ} \mathrm{C}$. The thermal electromotive force of the thermomodule was $6.5 \mathrm{mV} / \mathrm{K}$ and the sensitivity to temperature was $4 \times 10^{-5} \mathrm{~K}$. The whole volume of Al-blocked calorimeter is $46 \times 55 \times 43$ $\mathrm{cm}^{3}$.

In order to determine the heat of mixing, both heats of solution of the blended polymer $(1: 1)$ and the unblended polymer (from two kinds of homopolymers, 1:1) were measured. The mixing is assumed to take on a constant pressure and temperature, and thus the heat of mixing, $\Delta Q_{\mathrm{M}}$ may be given by the following equation:

$$
\Delta Q_{\mathrm{M}}=-\Delta H_{\mathrm{M}}=Q_{1}-Q_{2}
$$

where $Q_{1}$ and $Q_{2}$ are the heats of solutions of the unblended polymer and the blended polymer, respectively.

The results obtained are shown in Table I. The heats of mixing are exothermic for both the PVN-
PVAc and the PVN-EVAc systems. The compatibilities in the examined systems are thus confirmed thermodynamically.

The heat of mixing for PVN-PVAc system is greater than that for the PVN-EVAc system. As the volume changes, on mixing, are considered to be negligible small, ${ }^{4}$ this heat difference may be caused by the diluted effect of acetyl groups in the latter system.

As to the exothermic heats of mixing, Slonimskii ${ }^{9}$ has reported $5.9 \mathrm{cal} / 2 \mathrm{~g}$ for the cellose nitrate (N. cell)-cellose acetate system and $0.9 \mathrm{cal} / 2 \mathrm{~g}$ for the N. cell-poly (vinyl acetate) (PVAc) system. Ichihara and $\mathrm{Hata}^{10}$ also reported $1.8 \mathrm{cal} / \mathrm{g}$ for the N. cell-poly(methyl metacrylate), and $4.4 \mathrm{cal} /$ $\mathrm{g}$ for $\mathrm{N}$. cell-PVAc systems. The results shown in Table $I$ appear to be in good comparison with these reported values.

Acknowledgement. The authors are grateful to Dr. S. Miyata and Mr. Y. Takashima for providing the calorimeter, and to Dr. R. Kaneko for his comments.

\section{REFERENCES}

1. A. G. Shvarts, Colloid J., 18, 753 (1956).

2. S. Akiyama, Y. Komatsu, and R. Kaneko, Polym. $J ., 7,172$ (1975).

3. S. Akiyama, and R. Kaneko, Kobunshi Ronbunshu, 31, 12 (1974).

4. S. Akiyama, Bull. Chem. Soc. Jpn., 45, 1389 (1972).

5. S. Akiyama, N. Inaba, and R. Kaneko, Kobunshi Kagaku, 26, 529 (1969).

6. A. Nakajima, Kobunshi Kagaku, 6, 451 (1949).

7. E. Calvet and H. Prat, "Recent Progress in Microcalorimeter,' Pergamon Press, London, 1963.

8. Y. Takashima, K. Miasa, S. Miyata, and K. Sakaoku, “Analitical Calorimetry,"' Plenum Press, 1974, Vol. 3, p 1.

9. G. L. Slonimskii, J. Polym. Sci., 30, 625 (1958).

10. S. Ichihara, and T. Hata, Kobunshi Kagaku, 26, 249 (1969). 